\title{
INTERNATO DE ENFERMAGEM: CONQUISTAS E DESAFIOS NA FORMAÇÃO DO ENFERMEIRO
}

\author{
INTERNSHIP IN NURSING: VICTORIES AND CHALLENGES \\ IN THE TRAINING OF NURSES
}

INTERNADO DE ENFERMERÍA: CONQUISTAS Y DESAFÍOS

EN LA FORMACIÓN DEL ENFERMERO

\author{
Simone Domingues Garcia ${ }^{1}$ \\ Marli Terezinha Oliveira Vannuchi ${ }^{2}$ \\ Mara Lucia Garanhani ${ }^{3}$ \\ Mara Regina Lemes De Sordi ${ }^{4}$
}

Resumo O internato de enfermagem representa a consolidação da prática e da teoria aplicadas na realidade dos serviços de saúde e é alvo constante de discussões curriculares para seu aperfeiçoamento. O estudo aqui apresentado teve por objetivo descrever a história do internato de enfermagem de uma universidade pública do norte do Paraná e divulgar as conquistas e os desafios encontrados para a formação do enfermeiro. Tratou-se de pesquisa histórica e documental com abordagem qualitativa, realizada no ano de 2013. O internato de enfermagem foi construído com a integração das mudanças nacionais e as influências sociais e políticas enfrentadas pelas universidades públicas. Ressalta-se que a universidade desempenha importante papel como formadora de profissionais que, desde a concepção dos estágios, são envolvidos em discussões e planejamentos em relação à práxis, de modo a potencializar metodologias inovadoras e valorizar os campos de estágios. $\mathrm{O}$ internato de enfermagem em questão passou por diversos desafios ao longo dos anos na busca de seguir preceitos educacionais e do sistema de saúde e alcançou efetividade, confirmada pelos atores envolvidos. Palavras-chave internato não médico; enfermagem; educação em saúde; estudantes de enfermagem; serviços de integração docente-assistencial.
Abstract The internship in nursing represents the consolidation of practice and theory applied in the reality of health services, and improving it is a constant target of curricular discussions. The purpose of this study was to describe the history of the internship in nursing at a public university in northern Paraná state, Brazil, and to publicize the achievements made and challenges faced in the training of nurses. This was a historical and documentary research project with a qualitative approach carried out in the year 2013. The internship in nursing was built based on the integration of national changes and the social and political influences faced by public universities. It should be emphasized that the university plays an important role as a trainer of professionals who, from the conception of the internships, are involved in discussions on and in the planning of the praxis to potentiate innovative methodologies and to value the internship fields. The internship in nursing in question underwent several challenges over the years in the pursuit of educational and health system precepts, and it reached effectiveness, as confirmed by the players involved.

Keywords non-medical internship; nursing; education in health; nursing students; teacher-assistance integration services. 


\section{Introdução}

Ao discutir a formação em enfermagem no Brasil, busca-se encontrar um equilíbrio na construção do futuro profissional. Os alunos, ao ingressarem no ensino superior, necessitam de um universo de conhecimentos que implicam a atitude de construir e reconstruir, pois, além de qualificá-los tecnicamente, a universidade tem a missão de formar cidadãos conscientes, éticos e críticos (Souza e Paiano, 2011). Nesse contexto, destaca-se a necessidade de se fortalecer a prática interdisciplinar e aperfeiçoar a distribuição de conteúdo e carga horária das disciplinas destinadas à formação de competências administrativas, assim como a aproximação com a realidade profissional desde o início do curso por meio de práticas curriculares, para que seja oferecido um aprendizado significativo e consistente - capaz de incentivar os alunos a buscarem novos conhecimentos para um desempenho profissional determinado pelas transformações sociais (Souza e Paiano, 2011).

Afirma-se que os cursos de enfermagem enfrentam grandes desafios para incorporar na formação dos enfermeiros as propostas estabelecidas pelas Diretrizes Curriculares Nacionais (DCNs) do Curso de Graduação em Enfermagem, que incluem a inserção do aluno na prática dos serviços de saúde (Colenci e Berti, 2012). As DCNs preconizam que nos dois últimos semestres do curso de graduação ocorram os estágios supervisionados, correspondendo a $20 \%$ da carga horária do curso, realizados em hospitais gerais e especializados, ambulatórios, rede de atenção básica e comunidades (Brasil, 2001).

Cada instituição atribui um nome a esses estágios, como estágio profissionalizante, estágio em serviço ou internato de enfermagem. No estudo que deu origem a este artigo, usamos a terminologia 'internato de enfermagem', para os estágios supervisionados. Em sua história, os estágios curriculares passaram por modificações significativas, e só se tornaram práticas efetivas com o envolvimento crescente dos docentes e serviços de saúde nas reflexões, lutas e propostas acerca das mudanças curriculares, visando oferecer uma formação comprometida com a qualidade de ensino e a prestação de serviços de saúde à população (Dessunti et al., 2012).

Para que o internato de enfermagem ocorra, é fundamental valorizar a parceria entre academia e serviços de saúde, considerando que a condução do estágio é realizada por docentes do curso de enfermagem e os enfermeiros das unidades de estágio, que mantêm viva a discussão e a análise da práxis vivenciada pelo interno, desde seu início até a sua finalização, com avaliações participativas antes do estágio, durante sua realização e em seu final (Vannuchi et al., 2012).

O interno, ao atuar nas unidades dos serviços de saúde, vivencia o gerenciamento da assistência de enfermagem nas dimensões do saber, do saber-fazer, do saber-ser e do saber-conviver, possibilitando o desenvolvimento progressivo 
da independência e da segurança, itens fundamentais para a futura atuação profissional (Vannuchi et al., 2012).

Com as parcerias formadas entre instituições e diferentes trabalhadores, há um movimento significativo, que foi construída dia após dia na intenção de formar profissionais transformadores. Assim, os cursos de enfermagem dedicaram-se constantemente às práticas curriculares oferecidas aos alunos e os profissionais envolvidos, para que todos correspondessem às necessidades políticas sanitárias do país.

Para compreender a realidade vivenciada com os estágios curriculares nos cursos de enfermagem, é preciso revisitar a história a fim de que o passado demonstre os avanços e desafios vencidos ao longo dos anos, com a determinação de um tempo e um contexto, na busca do possível em face do desejável. Assim, o estudo aqui apresentado teve por objetivo descrever a história do internato de enfermagem de uma universidade pública do norte do estado do Paraná e divulgar suas conquistas e os desafios encontrados para a formação do enfermeiro.

\section{Método}

Optou-se pela pesquisa histórica e documental com abordagem qualitativa. $\mathrm{O}$ uso de documentos em pesquisa deve ser apreciado e valorizado, por ser possível extrair informações que justificam o seu emprego em várias áreas das ciências humanas, sociais e também na área da saúde, pois possibilita ampliar o entendimento de objetos cuja compreensão necessita de contextualização histórica e sociocultural (Sá-Silva, Almeida e Guindani, 2009).

A pesquisa foi realizada de maio a outubro de 2013. Como critério de inclusão, consideraram-se os documentos classificados em oficiais ou probatórios pela instituição e que tivessem citação referente ao internato de enfermagem, podendo ser da época da sua concepção, implantação ou implementação. Definiram-se como documentos oficiais aqueles produzidos e sancionados por órgãos competentes da universidade com poderes de colegiados consultivos, deliberativos e executivos; documentos probatórios, os produzidos por instâncias administrativas que, por sua veracidade, subsidiaram a estruturação do internato de enfermagem (Nascimento e Guimarães, 2007). Como critério de exclusão, os documentos oficiais e probatórios do curso de enfermagem que não apresentaram algum tipo de citação ao internato de enfermagem não foram incluídos.

Selecionaram-se fragmentos de documentos analisados para serem inseridos ao longo do estudo, como forma de enriquecer a pesquisa e fortalecer as vozes encontradas durante a evolução histórica da práxis do internato de enfermagem. Como critério de seleção desses fragmentos, consideraram-se a significância do internato de enfermagem relatado no documento e a clareza 
do texto, de modo a representar a importância da atividade para o curso e a universidade em questão.

Foram obtidos no colegiado do curso de enfermagem, Departamentos de Enfermagem e de Saúde Coletiva, os documentos pertencentes ao Centro de Ciências da Saúde, assim como na Pró-Reitoria de Graduação da universidade. Utilizaram-se documentos que datam do início do curso, em 1972, até 2012.

Após a seleção dos documentos, procedeu-se à leitura norteada por quatro fases: leitura exploratória, leitura seletiva, leitura analítica e, por fim, leitura interpretativa (Nascimento e Guimarães, 2007). A pesquisa foi aprovada pelo Comitê de Ética em Pesquisa da Universidade Estadual de Londrina (UEL) com o protocolo de número CAAE/ 03230268000-11.

\section{Resultados}

Analisou-se um total de quarenta documentos, diferenciados em oficiais e probatórios (nove oficiais e 31 probatórios), incluindo os cadernos de enfermagem, que passam a ter um novo número com alterações todos os anos, em razão do acompanhamento de discussões e mudanças significativas no sistema de saúde, e o livro do currículo integrado do curso na universidade em questão. Os documentos foram estudados como partes que se completam ao contar a história do internato de enfermagem, indicando que há uma sequência e complementação entre eles, como informações das diretrizes curriculares com o estipulado para a prática do estágio, discussões da formação do enfermeiro na prática e na teoria, acompanhamento docente dos alunos na prática, carga horária necessária, atividades executadas, desenvolvimento e parceria dos serviços de saúde, entre outras.

Os documentos com as avaliações foram encontrados de formas diversas, como em pequenas anotações pertencentes a outros documentos ou em cadernos do internato, além de ofícios da instituição e pautas de reuniões realizadas ao longo do estágio.

A riqueza e o potencial dos fatos encontrados na análise documental foram relevantes, porém deparou-se com a ausência de relatos que contemplassem os embates geradores de conflitos importantes para o alcance das mudanças. Essa constatação sugeriu que na maioria das vezes registrou-se apenas o resultado da obra e que as marcas carregadas por lutas e sonhos permaneceram apenas na memória dos atores, o que aumenta ainda mais a responsabilidade de quem retorna aos documentos para retirar sua essência e compartilhar com as próximas gerações.

Dentre os documentos, enfatizaram-se os dois livros sobre o currículo integrado do curso de enfermagem da UEL, os quais contemplam capítulos específicos do internato de enfermagem e são considerados marcos do início da história. Esses livros foram construídos pelos atores envolvidos no curso 
de enfermagem como um todo, e não somente do internato, permitindo aos leitores conhecerem parte do processo de formação dos alunos desde o início do curso. Com relação ao internato, os capítulos explicitam o desejo de sua implantação, a forma de planejamento perante as necessidades encontradas nos serviços de saúde, os relatos de atores envolvidos na construção e condução, o estabelecimento das normas para a instituição e suas modificações conforme a necessidade apresentada, ao se considerar o sistema de saúde vigente.

Caracterizado como um rico período de transição, o internato de enfermagem marca a mudança do papel de estudante para o de enfermeiro, uma vez que o interno permanece ao longo de 12 semanas em uma única unidade hospitalar e mais 12 semanas em uma unidade de atenção básica, o que possibilita ao aluno vivenciar o processo de trabalho dessas unidades e perceber e compartilhar o papel dos enfermeiros responsáveis por esses locais (Vannuchi et al., 2012).

Desde o início do internato, houve o estímulo à fala e à escrita dos alunos perante o aprendizado, porém os documentos demonstraram com mais clareza que após a inserção do currículo integrado, o qual passou a preconizar a construção do portfólio pelos internos, houve uma valorização maior pelos alunos dos instrumentos escritos, como manuais, protocolos, rotinas do processo de trabalho, além das vivências nas unidades durante todo o internato - já que passaram a registrar informações importantes identificadas no seu desenvolvimento pessoal no portfólio para posteriormente utilizá-lo como ferramenta de trabalho. Essa construção representou uma linha de desenvolvimento importante para cada um deles, que conseguiam visualizar o seu crescimento ao olhar para o portfólio.

$\mathrm{O}$ internato de enfermagem foi antecedido por um rico processo de discussão entre docentes, enfermeiros dos serviços de saúde e representantes da comunidade, que além de fomentarem mudanças construíram ricas anotações e diversos documentos.

Entre os fragmentos documentais que representam o acompanhamento da universidade as necessidades do sistema de saúde, pôde-se destacar:

A escola se organiza em função das necessidades de saúde da população e deverá ter por base a integração docente-assistencial. Fundamenta-se em um marco teórico, em teorias e conceitos que orientam seus programas e define seu papel em face a realidade sócio-política e econômica (Universidade Estadual de Londrina, [198-], p. 4).

A parceria entre a universidade e os serviços de saúde traz benefícios para os internos, que vivenciam intensamente a realidade da prática da enfermagem e o papel do enfermeiro na condução da equipe (Vannuchi et al., 2012, p. 185). 
Todos os anos, antes de iniciar o internato, há uma oficina de trabalho com o objetivo de programar a sua condução, e nela todos os atores podem expor suas opiniões, em um espaço rico de compartilhamento e descobertas. Há encontros semanais entre internos, docentes e enfermeiros de campo nas unidades de estágio, para acompanhar de perto a evolução dos alunos, além de reuniões mensais entre todos os enfermeiros e docentes, finalizando o internato com uma reunião de avaliação e fechamento do processo.

Em relação aos campos de estágios, encontrou-se documentado:

Essas unidades devem ser espaços de produção e construção de novos conhecimentos e práticas voltadas para integralidade da atenção à saúde. Para isso, é necessário um processo de preparo e manutenção, com encontros frequentes e canais de comunicação que permitam a utilização dos ruídos, desconfortos e conflitos como insumos para intensificar o aprendizado e identificar as necessidades de ofertas para aprendizagem e aprimoramento do trabalho em saúde (Dessunti et al., 2012, p. 22).

$\mathrm{Na}$ análise cronológica dos documentos, foi possível encontrar todos os serviços utilizados de campo de estágio ao longo dos anos, sendo identificados serviços que por influência política do momento fizeram e desfizeram parceria, outros que cresceram e abriram novas portas para a universidade, em um movimento constante de relacionamento político-social vital para o amadurecimento de todos os envolvidos.

Em relação aos atores mencionados nos documentos, o número foi significativo. Houve grande rotatividade de enfermeiros de serviços envolvidos no internato; já entre os docentes, o grupo foi mais estável. Cada um contribuiu com suas diferenças e experiências, e só foi possível contar a história devido ao esforço e dedicação individual. Esses atores ora construíram os documentos, ora discutiram e fizeram parte de debates que seriam inseridos nos relatos, de modo a permitir que o internato acontecesse na prática dos serviços de saúde e na instituição de ensino concomitantemente.

A distribuição de carga horária curricular representa um desafio constante a todas as instituições de ensino em enfermagem, dada a necessidade de contemplar os conhecimentos preestabelecidos juntamente com as práticas e os estágios. A carga horária estabelecida pelas DCNs para os estágios foi pautada no tempo mínimo necessário para tornar possível ao aluno vivenciar experiências formadoras essenciais e para que o enfermeiro e docente, como orientadores, conduzissem o processo para o desenvolvimento e o amadurecimento desse aluno dentro do campo de estágio (Brasil, 2001).

Entre os principais aprendizados encontrados, está a reflexão sobre a prática. Os internos são parceiros dos enfermeiros de campo, agregando e fazendo a diferença pelos questionamentos que apresentam; provocam movi- 
mentos positivos no cotidiano das unidades e no envolvimento com pesquisas científicas e até a formulação de artigos científicos com temas relevantes para a prática diária.

Por fim, os debates proporcionados por esses atores serviram de estímulo para as mudanças curriculares que vieram a seguir, com destaque para a implantação do currículo integrado, que passou a contemplar o internato com o último módulo do curso de enfermagem (Vannuchi et al., 2012).

\section{O caminho do internato de enfermagem: a construção de uma história}

Buscou-se apresentar a discussão de forma a mostrar que as conquistas e os desafios no caminho trilhado pelo internato de enfermagem se entrelaçam, já que para se alcançarem conquistas e sucesso com realizações na práxis citada é preciso enfrentar desafios constantes.

Os conflitos surgidos nos grupos e pouco descritos nos documentos têm caráter positivo quando utilizados como fatores desencadeantes de mudanças, impulsionando o crescimento pessoal, coletivo e organizacional, bem como a inovação e a produtividade. Ao lidar com o conflito de forma coletiva, criam-se espaços para a autorreflexão e possibilita-se a análise das mudanças geradoras de transformações que impulsionam novas práticas, como ocorreu no internato de enfermagem (Gil, 2008).

Sem dúvida, compreendeu-se que os conflitos que emergiram durante a construção, implantação e implementação do internato contribuíram para a sua consolidação, apesar da instabilidade gerada no momento em que o conflito se instalou. As normas seguidas durante o internato consideram a evolução dos alunos a cada semana, pontuando questões gerenciais e assistenciais encontradas no campo do estágio e comportamentais, de modo a permitir que os internos compartilhem momentos de ansiedade, dúvidas e questionamentos que fazem parte do processo de amadurecimento profissional.

Segundo Cotta, Mendonça e Costa (2011, p. 415-421), entre os recursos inovadores do processo de ensino-aprendizagem e avaliação destaca-se o portfólio como instrumento-estratégia de estímulo ao pensamento reflexivo. O portfólio permite ao educando documentar, registrar e estruturar os processos de sua própria aprendizagem, uma vez que a construção se pauta na pactuação entre educador e educando, de forma a possibilitar o trabalho colaborativo na articulação e na solução de problemas complexos. O portfólio também incentiva o aluno a colecionar suas reflexões e impressões sobre a disciplina, opiniões, dúvidas, dificuldades, reações aos conteúdos e aos textos estudados, às técnicas de ensino, sentimentos e situações vividas nas relações interpessoais. Oferece subsídios para a avaliação do estudante, do educador, 
dos conteúdos e das metodologias de ensino-aprendizagem, assim como para se estimar o impacto da própria disciplina.

É possível referir que não existe absolutismo nas metodologias e ferramentas de ensino. Elas requerem sinergia umas com as outras para fornecer a maior completude possível na aprendizagem do educando, respeitando-se a sua autonomia. Portanto, as metodologias devem acompanhar as transformações mundiais e locorregionais (Ribeiro e Medeiros Júnior, 2016).A universidade em questão sempre se preocupou, mesmo antes do currículo integrado, em inserir o aluno nos campos de estágios durante toda a graduação, para que ele não se sentisse lançado em um estágio obrigatório apenas no final do curso, e sim pudesse desenvolver habilidades que o levassem a assumir uma postura autônoma, mas não autossuficiente, sabendo dialogar com o outro e crescer com as opiniões divergentes das suas. Sabe-se que há grandes benefícios em razão do contato de graduandos com ambientes extrauniversitários ao longo da formação, e para que isso ocorra precisa-se desenvolver discussões constantes sobre as metodologias de ensino (Eder e Schwartzman, 2011).

Para estimular o desenvolvimento dos alunos, é essencial o preparo dos docentes, o que envolve a compreensão do processo educativo dos adultos, como a provisão de procedimentos e recursos para facilitar que aprendizes adquiram competências. $\mathrm{O}$ docente precisa discutir a formulação de políticas internas que transmitam definição da missão, filosofia social, compromisso das organizações e avaliação da eficácia organizacional, entre outros temas relevantes (Draganov e Sanna, 2014).

Ressalta-se que o índice de crescimento de escolas de formação de enfermeiros no Brasil aumentou consideravelmente e, em consequência, o número de docentes aumentou para atender à demanda. Com esse aumento súbito, é preciso discutir os estímulos apresentados pelas instituições na formação dos docentes (Draganov e Sanna, 2014).

Em relação às dimensões na formação do enfermeiro, que incluem a do conhecimento relacionado ao saber e à práxis, a qual diz respeito ao fazer no processo de cuidar em enfermagem, ambos os livros do currículo integrado da universidade que contemplam capítulos do internato deixaram clara a defesa desses pressupostos na análise. É durante a práxis que o saber torna-se um dos elementos que utilizamos no exercício da profissão de enfermagem, na perspectiva da ação por meio de competência, habilidade, persistência, paciência e disponibilidade para agir consciente e intuitivamente (Spagnol et al., 2010).

Os atores do internato de enfermagem, em toda a sua trajetória, demonstraram coragem para acompanhar os acontecimentos relativos às áreas de educação e saúde, além de incorporarem, em 1995, determinações que seriam apresentadas somente em 2001 nas DCNs, de modo a nortear a formação dos enfermeiros ante os desafios do Sistema Único de Saúde (SUS). Tal panorama demonstra que o curso de enfermagem da instituição não permaneceu está- 
tico em relação ao sistema de saúde e educacional vigente, o que contribuiu consideravelmente no processo de aplicação de estratégias educacionais direcionadas aos estágios profissionalizantes.

As iniciativas que soam internamente nos cursos de graduação por força dos atores envolvidos devem ser valorizadas, já que surgem para corresponder a uma necessidade visualizada por quem enfrenta a realidade diariamente, sendo mais positiva e com mais resultados diante das mudanças necessárias.

Quando as mudanças são impostas de forma não participativa, apenas correspondendo a questões hierárquicas, a resistência apresentada pelos envolvidos é maior. Ressalta-se que ambas as formas de mudanças, internas ou externas, podem gerar situações desafiantes, sendo essencial o acompanhamento pelos profissionais envolvidos. O que se vivenciou durante a implementação do internato foi que a força demonstrada internamente fez com que a reestruturação curricular proposta anos depois fosse impulsionada com maior facilidade, em razão de suas propostas corresponderem ao que já estava sendo traçado.

O internato de enfermagem tem buscado a formação de enfermeiros comprometidos com uma identidade e representatividade visível às diversas esferas sociais, para dessa forma alcançar o reconhecimento da profissão. O enfermeiro precisa ser capaz de compreender e participar de decisões mais complexas, mobilizando um saber construído na interação do indivíduo com os problemas surgidos e com os diferentes grupos, o que possibilita uma visão globalizada e atualizada de sua realidade (Pai, Schrank e Pedro, 2006).

Entre um dos maiores desafios está o de formar cidadãos participativos e capazes de conviver uns com os outros e com o ambiente cada vez mais complexo - e com demandas cada vez maiores na produção de bens materiais e simbólicos - num mundo globalizado e excludente, por isso é fundamental que o enfermeiro esteja preparado para as interações e os desafios constantes (Sgarbi et al., 2015).

Foi um desafio, durante o processo de construção, manter a homogeneidade do grupo, dada a participação instável dos atores, necessitando-se da permanência e da insistência constante de determinados docentes para garantir que o internato caminhasse em estado de aprimoramento e não de recomeço a cada encontro.

A construção coletiva que ocorreu desde o início do internato foi destaque entre as lições aprendidas e permanece viva ao longo do tempo, enfrentando desafios, conflitos, contextos diferentes e mudanças de gerações, porém os enfermeiros dos serviços e docentes continuam juntos buscando estratégias de fortalecimento dessa parceria. Esse movimento de integração é mostrado nos documentos conforme fragmento a seguir:

As oficinas partiram da reflexão coletiva da prática do enfermeiro nos diferentes campos de atuação, determinando as atividades imprescindíveis na formação do 
estudante. Foram realizadas discussões por área num primeiro momento, com posterior socialização dos produtos (Universidade Estadual de Londrina, [198-], p. 3).

A manutenção da relação entre enfermeiros de campo e enfermeiros docentes exige tempo precioso de ambos, sendo necessários estratégias inovadoras e meios de estímulos de participação nas oficinas e reuniões realizadas. Os atores envolvidos precisam compreender que é possível aprimorar ainda mais, e que é na parceria com todos que reside o sucesso do internato.

Notou-se que existe a necessidade de se avançar na ampliação dos espaços de diálogo com maior envolvimento dos atores nos distintos cenários e decisões compartilhados, ressaltando-se a complexidade que envolve a lógica de integração academia-serviço, ao se considerar que nela se incluem sujeitos distintos pela formação, pela faixa etária e até mesmo pela valoração social, além de pertencerem a diferentes serviços que, embora sejam complementares para a formação profissional, têm objetos de trabalho diferenciados (Sales, Marin e Silva Filho, 2015).

A luta contra a rotina e a estagnação precisa estar presente, para que os profissionais envolvidos compreendam que os alunos mudam, as gerações se transformam e os docentes e enfermeiros podem permanecer por anos, porém a compreensão de que é possível sempre aprender é fundamental. É frequente o controle do processo educativo por meio de definição rígida de conteúdos e instrumentos moldados, no entanto esse fato tolhe a criatividade e a autonomia para intervir em situações que envolvam alterações maiores no planejamento. É indispensável aos alunos compreenderem que a teoria os fortalecerá para atuarem na prática, mas a versatilidade é fundamental para saberem lidar nas diversas situações que surgem (Gil, 2008).

Com referência à quebra da rigidez dos conteúdos, a ousadia e a coragem também se tornaram exemplos na instituição, ao se perceber na história do internato de enfermagem o desejo dos docentes em abandonar as tradicionais formas de ensino na aplicação da disciplina denominada administração em enfermagem, buscando práticas e métodos pedagógicos inovadores - uma vez que a premissa do internato sempre foi formar enfermeiros críticos, reflexivos, preparados para resolver problemas que emanam da prática dos serviços.

Torna-se indispensável romper estruturas rígidas nas universidades, com início pela interação entre o corpo acadêmico, os serviços e as comunidades. A formação profissional não deve se limitar aos conhecimentos especializados, e sim agregar saberes de outros campos, respeitando-se as competências específicas de cada profissão, como forma de superar obstáculos e proporcionar uma atenção à saúde empenhada com a igualdade de direitos e a justiça social (Ribeiro e Medeiros Júnior, 2016).

Decorrida mais de uma década de aprovação das DCNs do ensino de enfermagem em nosso país, observam-se avanços importantes, particularmente 
no que se refere à construção/reconstrução de projetos pedagógicos/métodos pedagógicos dos cursos de graduação em enfermagem. Porém, muitos desafios ainda necessitam ser superados, ao se considerar o quantitativo de aproximadamente setecentos cursos de graduação em enfermagem em funcionamento em nosso país. Alguns cursos já vêm apresentando um processo de mudança no desenvolvimento das suas ações pedagógicas, mas percebe-se que essa não é a realidade da maioria, em que prevalece o enfoque do modelo segundo o qual a doença ainda é visualizada como um conjunto de sintomas que requerem intervenções (Ferreira, Pereira e Xavier, 2012).

Currículos organizados com o pensamento exclusivamente na colocação do profissional no mercado de trabalho não são satisfatórios, ao se afirmar que as exigências desse mercado não são estáveis, de modo que, se hoje é muito importante conhecer um avançadíssimo programa de computador, amanhã tal programa estará obsoleto. O mesmo se pode dizer de tudo: técnicas de cirurgia, nutrição ideal para crianças de certa idade, cuidados com pacientes na unidade de tratamento intensivo (UTI), por exemplo. Saber indagar, pensar, ler, ouvir, pesquisar, comunicar oralmente e por escrito, aperfeiçoar ou mudar um conceito diante de evidências novas, são valores que permanecem; portanto, é preciso que as maneiras de se conseguir desenvolver tais atitudes, ou práticas, sejam incorporadas na prática docente (Fonseca, 2011).

O enfrentamento dos desafios da contemporaneidade requer uma atualização pedagógica, não só da elaboração de projetos pedagógicos e desenhos curriculares, mas também de uma prática pedagógica que possibilite a formação de enfermeiros comprometidos com os graves problemas de saúde da nossa sociedade, o que significa não perder a perspectiva da integralidade da atenção, da equidade, da eficiência e da eficácia (Ferreira, Pereira e Xavier, 2012).

Um dos maiores desafios continua sendo o de aprofundar as discussões e demonstrar com clareza à comunidade universitária a necessidade da integração entre disciplinas e práticas curriculares, não se limitando somente àquele espaço, mas exigindo o desenvolvimento da competência de trabalhar a parte prática desse conhecimento num processo formativo de verdadeiros cidadãos, capazes de responder aos desafios apresentados pela sociedade no setor da saúde - de modo a promover oportunidades de reflexão sobre o trabalho/fazer pedagógico na saúde e na enfermagem (Ferreira, Pereira e Xavier, 2012).

A necessidade de mudança ecoa na formação de recursos humanos da saúde, em que o enfermeiro representa um importante papel social nas práticas educativas voltadas à população. Ressalta-se que a adequação do conhecimento aos serviços prestados à população com base nas necessidades sociais precisa estar em constante movimento, o que exige uma atualização e interesse vital das instituições de ensino. Assim, o enfermeiro em formação, na sua trajetória acadêmica, precisa apresentar diferentes aproximações com ações de educação em saúde e integração com os serviços, para que com as realidades regionais 
aprimore os requisitos necessários para ele adquirir as competências e habilidades específicas exigidas pelo curso (Oliveira et al., 2015).

Sobre a importante integração entre a academia, os serviços de saúde e a comunidade, é fundamental discuti-la constantemente para a formação profissional nos diversos níveis de atenção. Essa união é necessária para uma formação voltada às necessidades das pessoas e comunidades, segundo a lógica do SUS, para oportunizar aos estudantes o desenvolvimento da cidadania (Vannuchi et al., 2012).

Com a parceria existente entre interno, enfermeiro e docente, busca-se o compartilhar de novas descobertas e conhecimentos com profissionais capazes de tomar decisões, com vontade de aprender, atentos a sua capacidade de se comunicar com o estudante, de forma a oferecer informações relevantes, organizadas e com capacidade de produzir conhecimento (Demarzo et al., 2008).

A participação popular na discussão do internato continua frágil desde a sua concepção - e passa a ser mais evidente quando o aluno estagia nas unidades de atenção básica, devido a espaços mais concretos e propícios para a participação comunitária. A comunidade deve ser estimulada a participar de todos os serviços de saúde, com maior fortalecimento de espaços de integração nos ambientes hospitalares, que muitas vezes só se comunicam diretamente com a população por meio de crítica e reclamações, diferente do encontrado nos serviços de atenção básica.

A aprendizagem no trabalho em saúde é valiosa em todas as suas vertentes, espaços esses articulados para atender ao exigido pelo SUS. Espera-se assim mostrar que o internato de enfermagem finaliza o processo de formação na graduação da UEL com o intuito de formar enfermeiros com conhecimentos do que é e do que representa o sistema de saúde a que servimos. Para isso foi preciso também ousar no sentido de ampliar os cenários para a prática do internato, firmando e (re)afirmando parcerias essenciais para a efetividade da prática, de modo a evidenciar outra lição de aprendizado com o internato.

Ressalta-se que a formação de novos enfermeiros envolve outras vivências práticas, com o conhecimento das unidades dos serviços antes do internato. Assim, a discussão do proposto pelas DCNs, os compromissos exigidos pelo SUS e os serviços oferecidos na rede de atenção à saúde devem permear todos os anos da graduação, para que o aluno, ao aproximar-se da realização do internato, tenha familiaridade e discernimento da complexidade do sistema de saúde nacional dentro dos serviços.

No curso de enfermagem da UEL, os acordos com os campos são reafirmados anualmente, sendo necessário driblar os desafios que ocorrem, como influências políticas, principalmente nas escolhas das unidades básicas, a competição de campos com outras instituições de ensino e a dedicação de alguns enfermeiros de serviço na condução dos internos. Aqui fica a lição de que o 
internato sofre influência política constante e por isso precisa ser conduzido com cuidado, clareza, discernimento e parcerias.

É imprescindível reafirmar-se que para a aprendizagem efetiva e a prestação da assistência de enfermagem qualificada e humanizada é preciso que o aluno esteja inserido na equipe de cuidados de forma consciente e competente, utilizando seus conhecimentos técnicos e científicos, ao se considerar que a produção de saberes está nos espaços de saúde e é construída coletivamente (Demarzo et al., 2008).

Não basta somente o interno não faltar ao estágio; ele precisa ter compromisso e estar inserido na escala diária de sua unidade, participando do trabalho coletivo com base em uma educação mediada pelo trabalho.

É válido ressaltar que, independentemente do campo em que o interno irá atuar, a competência, os desempenhos e as habilidades são os mesmos e estão claramente explicitados no caderno do módulo do internato, documento analisado detalhadamente durante o estudo por mostrar sua evolução ao longo dos anos, servindo de orientação para todos os envolvidos. A competência estipulada para o internato de enfermagem converge para uma formação generalista e voltada para o gerenciamento da assistência de enfermagem, seja ela na área hospitalar, seja na de saúde coletiva.

Outra lição importante identificada nos documentos foi a defesa de que o internato não poderia ser um espaço para cumprir cargas horárias de módulos que o antecederam, e que o tempo de permanência do interno em uma única unidade de estágio hospitalar e depois em uma de atenção básica é fundamental para que ocorra a imersão em diferentes processos de trabalho. Assim, ele vivenciaria de fato o papel do enfermeiro na prática dos serviços.

Esse aluno, inserido no ambiente de trabalho, deve ser formado com capacidade de solucionar situações diversas que exigem perspicácia e posicionamento, mas também deve propor novas situações, pois é a invenção que traz a possibilidade do novo e está sempre implicada na imprevisibilidade, presente nos serviços e na experiência cotidiana do trabalhador. $\mathrm{O}$ ensino alicerçado no cuidado implica uma relação interpessoal, imprevisível, que não pode ser preestabelecida, pois é única e peculiar à pessoa humana e potencialmente criativa (Barbosa et al., 2013).

Ao interno de enfermagem da instituição, é oportunizada a construção de um planejamento em relação a questões levantadas na unidade de estágio. Ao se inserir no processo de trabalho e potencializar suas ações, o interno compreende que suas percepções são importantes para qualificar e aprimorar o ambiente em que está atuando.

Estimular o planejamento como ferramenta de trabalho é uma importante estratégia para preparar os internos para os diversos cenários de atuação. O planejamento tem sido utilizado para caracterizar as atividades dos enfermeiros 
visando à realização de melhores práticas de cuidado nos serviços de saúde e enfermagem por meio de ações, previsão e provisão de recursos necessários para assistência e potencialização das interações entre os profissionais da equipe (Silva et al., 2010).

As avaliações do internato em todas as suas fases visam ao aprimoramento do processo, correspondendo ao preconizado pelas DCNs, que consideram essencial a presença de aluno, enfermeiro e docente. Avaliar também oportuniza constantes atualizações por meio de novas propostas surgidas da realidade demonstrada com a participação de todos os envolvidos (Santos et al., 2013).

Foi possível encontrar entre as análises a contribuição da trajetória do internato para o ensino de enfermagem, no sentido de remeter o olhar para a história e ver o tanto que caminhamos e o que construímos com propostas inovadoras, aceitação de desafios, parcerias que permanecem firmadas entre o ensino e os serviços de saúde. Por fim, destaca-se que outras lições são tiradas anualmente do internato de enfermagem, e dentre as mais preciosas está a compreensão de que a prática não se encontra ideal ou consolidada, por isso o desejo de avançar deve estar sempre presente em todos os atores envolvidos.

\section{Conclusão}

O estudo aqui apresentado procurou ressaltar a relevância de se compartilharem as contribuições alcançadas com a prática do internato de enfermagem, tanto para a reconstrução da história do curso da universidade como para a reflexão de outras instituições, segundo seus processos de construção e reconstrução, haja vista que todos continuam enfrentando os desafios estabelecido pelas DCNs e pelo sistema de saúde vigente.

Mostrou-se que as mudanças, por menores que sejam, não existem sem o desejo e a força dos profissionais envolvidos, que devem buscar modificações em suas realidades, por vezes cristalizadas pela acomodação do tempo.

A presença do interno de enfermagem em diferentes cenários tem desestabilizado equipes no sentido de reavaliarem seus papéis e seus processos de trabalho. A história do internato é (re)construída todos os anos com novos profissionais e novos alunos em formação, estudantes esses que precisam do apoio das instituições de ensino e dos serviços de saúde para serem formados e preparados para enfrentar a realidade do cenário de saúde do Brasil.

A pesquisa procurou deixar claro que das lições e descobertas surgiram outras questões, como: o trabalho em equipe dentro do processo de enfermagem está ocorrendo de forma efetiva? Os internos estão conseguindo compreender a dimensão da gestão do cuidado durante o internato? Estamos realmente formando alunos capacitados para o SUS?

Verificou-se que os internos adquirem autonomia para realizarem suas atividades nas unidades, conseguindo construir ao longo das semanas uma 
visão ampla do sistema de saúde. A autonomia vem em conjunto com o processo do amadurecimento em relação ao papel dos enfermeiros, fortalecendoos para estar diante de mudanças que ocorrem diariamente nos campos de estágios e deixando-os seguros para irem em busca do seu primeiro emprego. O curso de enfermagem, no olhar de seus atores, compreende que a efetividade alcançada com o internato de enfermagem não significa que os desafios estejam vencidos, mas sim que o trabalho e o esforço de todos em relação ao exigido nacionalmente são válidos.

As lições evidenciadas parecem deixar claro que o internato de enfermagem se consolida com o passar do tempo, tornando-se sempre um novo desafio a sua reconstrução anual, que tem como eixo central a formação do enfermeiro alicerçada na parceria entre a academia e os serviços de saúde. Espera-se que os desafios e as superações observados na instituição instiguem a busca pela aprendizagem significativa, de modo a inspirar novas formas de vivenciar os estágios curriculares em enfermagem.

\section{Colaboradoras}

Simone Domingues Garcia é a responsável pela coleta de dados e redação do manuscrito, tendo participado de todas as etapas de sua elaboração. Marli Terezinha Oliveira Vannuchi participou da construção da proposta do trabalho, desenvolvimento da introdução, método, discussão e conclusão. Mara Lucia Garanhani contribuiu na construção da proposta do trabalho, método, discussão e conclusão. Mara Regina Lemes De Sordi participou da estruturação final do trabalho, método, discussão e conclusão.

Resumen El internado de enfermería representa la consolidación de la práctica y la teoría aplicadas en la realidad de los servicios de salud y es constante centro de discusiones curriculares para su perfeccionamiento. El estudio aquí presentado tuvo por objetivo describir la historia del internado de enfermería de una universidad pública del norte del estado de Paraná, Brasil, y divulgar las conquistas y desafíos encontrados para la formación del enfermero. Se trató de una investigación histórica y documental con enfoque cualitativo, realizada en el año 2013. El internado de enfermería se construyó con la integración de los cambios nacionales y las influencias sociales y políticas enfrentadas por las universidades públicas. Se destaca que la universidad desempeña un importante papel como formadora de profesionales que, desde la concepción de las pasantías, se involucran en discusiones y planificaciones con relación a la praxis, de forma de potencializar metodologías innovadoras y valorizar los campos de pasantías. El internado de enfermería en 
cuestión pasó por diferentes desafíos a lo largo de los años en la búsqueda de seguir preceptos educativos y del sistema de salud, y logró efectividad, confirmada por los actos involucrados.

Palabras clave internado no médico; enfermería; educación en salud; estudiantes de enfermería; servicios de integración docente-asistencial.

\section{Notas}

${ }^{1}$ Universidade Estadual do Oeste do Paraná, Curso de Bacharelado e Licenciatura em Enfermagem, Cascavel, Paraná, Brasil.

<sidomingues@yahoo.com.br>

Correspondência: Rua Riachuelo, 2.420, apto. 802, torre 1, CEP 85813310, Centro, Cascavel, Paraná, Brasil.

${ }^{2}$ Universidade Estadual de Londrina, Curso de Graduação em Enfermagem na área de Gerência de Enfermagem, Londrina, Paraná, Brasil.

$<$ marlivannuchi@gmail.com>

${ }^{3}$ Universidade Estadual de Londrina, Londrina, Paraná, Brasil.

$<$ maragara@hotmail.com>

${ }^{4}$ Universidade Estadual de Campinas, Faculdade de Educação, Campinas, São Paulo, Brasil. <maradesordi@uol.com.br>

${ }^{5} \mathrm{O}$ estudo faz parte da dissertação intitulada $\mathrm{O}$ internato de enfermagem da Universidade Estadual de Londrina e suas contribuições para a formação do enfermeiro (Garcia, 2013). 


\section{Referências}

BARBOSA, Guilherme C. et al. Política Nacional de Humanização e Formação dos Profissionais de Saúde: revisão integrativa. Revista Brasileira de Enfermagem, Brasília, v. 66, n. 1, p. 123-127, 2013.

BRASIL. Ministério da Educação. Conselho Nacional de Educação. Parecer CNE/CES n. 1.133/2001. Sobre diretrizes curriculares nacionais do curso de graduação em enfermagem, medicina e nutrição. Disponível em: < http:// portal.mec.gov.br/dmdocuments/ces1133.pdf > Acesso em: 5 maio 2016.

COLENCI, Raquel; BERTI, Heloísa W. Formação profissional e inserção no mercado de trabalho: percepções de egressos de graduação em enfermagem. Revista da Escola de Enfermagem da USP, São Paulo, v. 46, n. 1, p.158-166, 2012.

COTTA, Rosangela M. M.; MENDONÇA, Érica T.; COSTA, Glauce. D. Portfólios reflexivos: construindo competências para o trabalho no Sistema Único de Saúde. Revista Panamericana de Salud Publica, Washington, v. 30, n. 5, p. 415-421, 2011.

DEMARZO, Marcelo M. P. et al. Diretrizes para a integração ensino-serviço-comunidade na formação e atenção primária à saúde e medicina de família e comunidade. Revista de APS, Juiz de Fora, v. 11, p. 478-479, 2008. Disponível em: <http://sbmfc.org.br/media/ file/documentos/artigo_forum_formacao_final. pdf $>$. Acesso em: 5 maio 2016.

DESSUNTI, Elma M. et al. Contextualização do currículo integrado do curso de enfermagem da Universidade Estadual de Londrina. In: KIKUCHI, Edite; GUARIENTE, Maria H. D. M. (orgs.). Currículo integrado: a experiência do curso de enfermagem da Universidade Estadual de Londrina. Londrina: UEL, 2012. p. 19-31.
DRAGANOV, Patrícia B.; SANNA, Maria C. Avaliação das competências dos professores para administrar programas educativos para adultos. Escola Anna Nery Revista de Enfermagem, Rio de Janeiro, v. 18, n. 1, p. 167-174, 2014.

EDER, Maria L.; SCHWARTZMAN, Gisela. Formar o recetar: el aporte de la asesoría pedagógica para transformar las prácticas docentes. Revista del Hospital Italiano de Buenos Aires, Buenos Aires, v. 31, n. 3, p. 93-98, 2011.

FERREIRA, Rogério M. F.; PEREIRA, Maria M. N.; XAVIER, Sandra M. M. A formação contínua e o desenvolvimento de competências no professor. Revista de Enfermagem UFPE [online], Recife, v. 6, n. 9, p. 2.298-2.306, 2012. Disponível em: <http://www.revista.ufpe.br/ revistaenfermagem/index.php/revista/article/ view/2735/pdf_150>. Acesso em: 5 maio 2016.

FONSECA, Maria C. V. O conhecimento nas instituições de ensino: uma revisão de literatura e reflexões para os docentes. Revista Práxis, Volta Redonda, v. 3, n. 5, p. 63-65, 2011.

GARCIA, Simone D. O internato de enfermagem da Universidade Estadual de Londrina e suas contribuições para a formação do enfermeiro. 2013. 96f. (Mestrado em Enfermagem) - Universidade Estadual de Londrina, Programa de Pós-Graduação em Enfermagem, Londrina. 2013.

GIL, Antonio C. Métodos e técnicas de pesquisa social. 6. ed. São Paulo: Atlas, 2008.

NASCIMENTO, Lúcia M. B.; GUIMARÃES, José A. C. A organização da informação jurídicodigital e os avanços teóricos da diplomática: uma reflexão acerca da eficácia probatória do documento. Informação \& Informação, Londrina, v. 12, n. 2, p. 233-248, 2007. Disponível 
em: <http://www.uel.br/revistas/uel/index. php/informacao/article/view/1762>. Acesso em: 5 maio 2016 .

OLIVEIRA, Marília R. et al. Concepção de graduandos de enfermagem sobre a prática de educação em saúde em primeiros socorros. Revista da Rede de Enfermagem do Nordeste, Fortaleza, v. 16, n. 2, p. 150-158, 2015.

PAI, Daina D.; SCHRANK, Guisela; PEDRO, Eva N. R. O enfermeiro como ser sociopolítico: refletindo a visibilidade da profissão do cuidado. Acta Paulista de Enfermagem, São Paulo, v. 19, n. 1, p. 82-87, 2006.

RIBEIRO, Iramara L.; MEDEIROS JÚNIOR, Antônio. Graduação em saúde, uma reflexão sobre ensino-aprendizado. Trabalho, Educação e Saúde, Rio de Janeiro, v. 14, n. 1, p. 33-53, 2016.

SALES, Patrícia R. S.; MARIN, Maria J. S.; SILVA FILHO, Carlos R. Integração academia-serviço na formação de enfermeiros em um hospital de ensino. Trabalho, Educação e Saúde, Rio de Janeiro, v. 13, n. 3, p. 675-693, 2015.

SANTOS, José L. G. et al. Práticas de enfermeiros na gerência do cuidado em enfermagem e saúde: revisão integrativa. Revista Brasileira de Enfermagem, Brasília, v. 66, n. 2, p. 257263, 2013.

SÁ-SILVA, Jackson R.; ALMEIDA, Cristóvão D.; GUINDANI, Joel F. Pesquisa documental: pistas teóricas e metodológicas. Revista Brasileira de História \& Ciências Sociais, Porto Alegre, v. 1, n. 1, p. 1-15, 2009. Disponível em: <http://www.rbhcs.com/rbhcs/article/ view/6/pdf $>$. Acesso em: 5 maio 2016.
SGARBI, Antonio D. et al. A alfabetização científica no contexto da sustentabilidade: discussão sobre uma formação de agentes socioambientais. Revista Práxis, Volta Redonda, v. 7, n.14, p. 19-26, 2015.

SILVA, Mary G. et al. Processo de formação do(a) enfermeiro(a) na contemporaneidade: desafios e perspectivas. Texto \& Contexto Enfermagem, Florianópolis, v. 19, n. 1, p. 176-184, 2010.

SOUZA, Flávia A.; PAIANO, Marcelle. Desafios e dificuldades enfrentadas pelos profissionais de enfermagem em início de carreira. Reme: Revista Mineira de Enfermagem, Belo Horizonte, v. 15, n. 2, p. 267-273, 2011.

SPAGNOL, Carla A. et al. Situações de conflito vivenciadas no contexto hospitalar: a visão dos técnicos e auxiliares de enfermagem. Revista da Escola de Enfermagem da USP, São Paulo, v. 44, n. 3, p. 803-811, 2010.

UNIVERSIDADE ESTADUAL DE LONDRINA (UEL). Coordenadoria de Assuntos de Ensino de Graduação. Processo n. 4. Londrina: UEL, [198-].

VANNUCHI, Marli T. O. et al. O internato de enfermagem no currículo integrado. In: KIKUCHI, Elma M.; GUARIENTE, Maria H. D. M. (orgs.). Currículo integrado: a experiência do curso de enfermagem da Universidade Estadual de Londrina. Londrina: UEL, 2012. p. 179-192.

Recebido em 16/05/2016. Aprovado em 27/06/2017. 